\title{
Hernández Arregui y la invención de una historiografía para la izquierda peronista
}

Hernandez Arregui and the invention of a historiography for the Peronist left

Valeria A. Caruso a

E-mail: caruso.valeria@gmail.com https://orcid.org/0000-0003-3689-8839 iD

a Universidad de Buenos Aires, Instituto de Investigaciones de Estudios de Genero, Facultad de Filosofía y Letras, Buenos Aires, 


\section{RESUMEN}

Este trabajo tiene por objeto analizar el proceso de configuración de una historiografía de la izquierda peronista, luego de 1955, observable en las intervenciones intelectuales realizadas por Juan José Hernández Arregui por medio de su ensayística histórica. En primer lugar, se exploran las condiciones de posibilidad que intervinieron en el proceso de emergencia de esa ensayística histórica, así como sus características. En segundo término, se analizan las acciones desplegadas por este intelectual para difundir y legitimar su concepción sobre el pasado nacional y el peronismo. Esta indagación sostiene que las luchas por la vigencia del peronismo durante el periodo en el que esa fuerza política estuvo proscripta fueron constitutivas de las formas que ensayó Hernández Arregui para abordar el pasado argentino.

\section{PALABRAS CLAVE}

Hernández Arregui. Izquierda peronista. Historiografía.

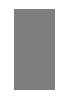

\section{ABSTRACT}

This article aims to analyze the process of configuration of a historiography of the Peronist left, after 1955, that can be found in the intellectual interventions made by Juan José Hernández Arregui through his historical essays. This article starts by exploring the conditions that affected the process of emergence of this essay and their characteristics. Following, the actions employed by Hernández Arregui to spread and legitimize his conception of the national past and Peronism are analyzed. This article argues that the struggles for the validity of Peronism during the period when this political force was banned were constitutive of the ways that this author tried to address the Argentine past.

\section{KEYWORDS}

Hernández Arregui. Peronist Left. Historiography. 


\section{İntroducción}

Tulio Halperín Donghi (1996), en su clásico trabajo sobre el revisionismo histórico, denominó como "neoreviosionistas" las reelaboraciones del pasado que emergieron a fines de 1950 y se consolidaron durante la década de 1960. Cuestionaba el uso que los neoreviosionistas realizaban del pasado nacional, pues, en su opinión, siempre lo adecuaban a sus proyecciones políticas, anteponiéndolas a las claves de verdad que portaban las fuentes de la historia. La razón política, acusaba entonces Halperín, antes que la histórica, forzaba las comprensiones sobre lo pretérito nacional en las obras de Jorge Abelardo Ramos, Rodolfo Puiggrós, Eduardo Astesano, Hernández Arregui y la dupla Rodolfo Ortega Peña y Eduardo Luis Duhalde. Pocos motivos encontraba el hacedor de Revolución y guerra para no reducir esas narraciones sobre el pasado a las de la poética política de Francisco Urondo en Adolecer.

Una lectura más compleja sobre el revisionismo histórico que se consolida en la década de 1960 se encuentra en el análisis que realiza Fernando Devoto (2004). En este trabajo, Devoto analiza las características del contexto en el que emerge esta corriente historiográfica, diferenciándola del revisionismo de los años 1930. También examina los núcleos temáticos abordados por esta nueva historiografía, aunque equiparando en un mismo rango de entendimiento las elaboraciones sobre el pasado realizadas por referentes de la izquierda nacional (IN) como Jorge Abelardo Ramos a las proyectadas por los pensadores de la izquierda peronista (IP), presentes en las obras de Hernández Arregui, Ortega Peña y Duhalde. El problema de este enfoque reside, justamente, en la equiparación de una y otra interpretación del pasado, dado que impide acceder a las particularidades de la empresa historiográfica emprendida por aquellos actores que construyeron una interpretación del pasado argentino en perspectiva con los nuevos entendimientos que desplegaron sobre el peronismo como vector de la liberación nacional. Esta última cuestión diferencia de manera sustancial la lectura del pasado realizada por Ramos sobre el fenómeno peronista y su lugar en la historia argentina que, en cierta medida, condensa el cambio de posición que se dio en un sector de la intelectualidad argentina vinculada con las izquierdas locales señalado por Carlos Altamirano (2001) en Peronismo y cultura de izquierda. ${ }^{1}$

Consideramos que Hernández Arregui, primero, y luego Ortega Peña y Duhalde colaboraron en la configuración de una interpretación del pasado nacional que sentó

${ }^{1}$ Recordemos que, en estos ensayos, Altamirano documenta en mayor grado el proceso de acercamiento de distintos referentes de las izquierdas al peronismo, aunque no así el proceso formativo de la IP ni las características específicas de sus intelectuales. 
las bases de una historiografía de la IP. ${ }^{2}$ Si bien autores como Goebel $(2005,2013)$ y Stortini (2004) han analizado las características del revisionismo histórico durante la década de 1960, aun no contamos con una síntesis interpretativa que permita acceder a las particularidades de esta empresa historiográfica en términos contextuales. Quien más se ha aproximado a la cuestión ha sido Omar Acha (2009), otorgando un espacio de visibilidad a esta historiografía que, en otros trabajos, le había sido negada.

En ese sentido, este trabajo tiene por objeto analizar las características y condiciones de posibilidad que intervinieron en la configuración de una historiografía de la izquierda peronista luego de 1955 a partir del examen de la obra de Juan José Hernández Arregui. Si bien la vida y obra de este intelectual peronista ha sido estudiada por diversos autores (PIÑEIRO IÑIGUEZ 2007; GALASSO 2012), consideramos pertinente indagar las características de los aportes historiográficos realizados por este autor.

Una de las hipótesis que plantea esta indagación sostiene que las luchas por la vigencia del peronismo fueron constitutivas de las formas de abordar el pasado argentino que ensayó Hernández Arregui, en tanto precisó recurrir a lo pretérito para explicar la actualidad del movimiento proscripto, inscribiéndolo en una relectura del pasado nacional en la que el peronismo fue interpretado como la reactualización de las gestas populares decimonónicas contra la opresión imperialista en el Río de la Plata. Asimismo, buscó destacar la trascendencia del movimiento proscripto en la historia de las izquierdas argentinas argumentando sobre las razones por las cuales el peronismo era la expresión histórica y presente de la verdadera izquierda nacional de la Argentina. Una segunda hipótesis sostiene que la construcción de esta empresa historiográfica funcionó como la plataforma desde la cual este pensador erigió sus credenciales intelectuales en un contexto cultural vedado para los peronistas.

Consideramos pertinente ensayar una aproximación que posibilite examinar el proceso constitutivo de esta historiografía desde un abordaje contextual. Esto implicaría recuperar, en primer término, las perspectivas metodológicas brindadas por Quentin Skinner (2000) para el estudio de las ideas políticas. La tendencia a la "prolepsis", tan vigente en la historiografía argentina sobre el pasado reciente, fuerza los análisis históricos sobre las ideas del pasado al someterlos a moldes interpretativos ajenos a la época de los actores, una época en la que la toma de posición política era sustancial para cualquier intervención intelectual que se apreciase de tal. Entendemos que examinar

Por cuestiones de extensión no podemos ocuparnos aquí de analizar los aportes de Ortega Peña y Duhalde a la corriente historiográfica iniciada por Hernández Arregui. Las contribuciones de esos autores serán tratadas en un trabajo de próxima publicación. 
los actos elaborados por los actores que son objeto de nuestra pesquisa y los efectos de sus acciones en el contexto histórico en el que fueron expresados puede ayudarnos a comprender mejor los procesos pretéritos que estudiamos. Al respecto, conviene no perder de vista que, mientras el peronismo gobernó el país (1946-1955), no precisó de la elaboración de una narrativa histórica específica y diferenciada a la instituida hasta el momento. De hecho, no alentó las empresas del revisionismo histórico situado en el Instituto de Investigaciones Históricas "Juan Manuel de Rosas", sino que, por el contrario, anudó la significación de sus acciones de gobierno a la cosmogonía de la historiografía liberal vigente.

Lo expuesto hasta aquí nos introduce en la segunda cuestión del enfoque contextualista que nos interesa recuperar a fines de esta indagación, referida a la propuesta teóricometodológica de John G. A. Pocock (2011) sobre el quehacer historiográfico. Para Pocock, "la historiografía es la elaboración de relatos (a lo que hay que añadir la construcción de contextos) sobre ciertos tipos de acción" en los que "el contexto siempre es parcialmente (nunca del todo) producto de las acciones realizadas en él" (2011, p. 274). Esos relatos, productos de la acción, engendran a su vez nuevas acciones en el contexto del que son parte y producto, permitiendo a los actores otorgarles inteligibilidad a las circunstancias que los rodean. Asimismo, Pocock nos recuerda que la política es constitutiva de toda perspectiva historiográfica, dada la necesidad de determinados actores de comprender su devenir en tanto sujetos y partícipes de la historia que habitan y realizan con sus actos. Esta cuestión no implica una versión uniforme sobre lo acontecido, sino que, por el contrario, emerge del despliegue de distintos entendimientos sobre lo pretérito que el autor confronta con "una estructura política capaz de contar su propia historia" (2011, p. 275). Esa historiografía emergente acciona críticamente cuestionando las formas instituidas de entender lo sucedido, compitiendo por la interpretación dominante del pasado en un contexto plagado de disputas por interpretar lo acontecido. Es decir, la emergencia de estos relatos historiográficos, a la vez que se da para contrarrestar las versiones "oficiales" sobre el pasado, busca renarrar lo sucedido, lo que está sucediendo y lo que, potencialmente, puede suceder como manera de intervenir en el presente.

La recuperación de estas perspectivas teóricas puede colaborar para la comprensión del proceso formativo de la historiografía de la IP. Este tipo de abordaje permitirá observar cómo en el hacer de esas narrativas se fueron creando nuevos marcos de inteligibilidad del pasado nacional como medio de intervención pública y política. Las demandas del contexto político que, a juicio de sus artífices, señalaban la centralidad de Perón, las masas y el peronismo, requirieron de una nueva narrativa de la historia argentina que hiciera inteligible esas presencias y también las proyecciones de futuro 
que a partir de ellas realizaban. Esto se hace más evidente si consideramos que, desde 1955 , las maneras de interpretar el pasado argentino fueron renarradas por referentes intelectuales identificados con el movimiento proscripto en su intención de explicar la trascendencia del fenómeno peronista en la historia argentina. ${ }^{3}$

De allí que resulte pertinente examinar los contextos que creó la narrativa histórica pergeñada por Juan José Hernández Arregui durante el periodo de la proscripción al peronismo como uno de los elementos constitutivos de la IP como cultura política. Por "cultura política", entendemos "un conjunto de representaciones que cohesionan a un grupo humano en el plano político, es decir una visión del mundo compartida, una lectura común del pasado, una proyección hacia el futuro, vivida en grupo" (SIRINELLI 1999, p. 462). En ese sentido, consideramos que las renarraciones del pasado argentino elaboradas por Hernández Arregui contribuyeron a la gestación de nuevos marcos de inteligibilidad sobre la actualidad del movimiento por entonces proscripto que alimentaron la imaginación histórica y política de los y las peronistas. ${ }^{4}$

En función de lo anteriormente planteado, la pesquisa se organiza en dos apartados. En el primero, se exploran las condiciones de posibilidad que intervinieron en el proceso de emergencia de esta ensayística histórica, así como sus características. En el segundo, se analizan las acciones desplegadas por Hernández Arregui para difundir y legitimar su concepción sobre el pasado nacional y el peronismo.

\section{Hernández Arregui: la invención de una tradición historiográfica}

Juan José Hernández Arregui (1912-1974) inició su formación universitaria en la Facultad de Derecho de la Universidad de Buenos Aires, aunque finalizó sus estudios en Filosofía en la Universidad Nacional de Córdoba y, bajo la dirección de Rodolfo Mondolfo, obtuvo su doctorado en esa disciplina. Las vinculaciones de uno de sus tíos con el sabattinismo cordobés le habilitaron sus primeras conexiones políticas. En Buenos Aires, fue cercano al grupo Fuerza de Orientación Radical de la Joven Argentina (FORJA) y acompañó el pasaje de varios de sus miembros del radicalismo al peronismo, 
desafiliándose definitivamente de la Unión Cívica Radical (UCR) en 1947. ${ }^{5}$ Hasta 1955, este filósofo peronista se desempeñó como profesor titular concursado en la Universidad Nacional de La Plata, cargo del cual fue cesanteado por la autodenominada "Revolución Libertadora". ${ }^{6}$ El hecho de que hubiera ocupado un cargo universitario como un "profesor flor de ceibo" sirvió de mote para fundamentar su desvinculación de las formalidades de la vida universitaria, desestimándose sus méritos intelectuales y reduciéndose su trayectoria académica a su adhesión al "régimen" depuesto.7

Al respecto, el editor Arturo Peña Lillo, al rememorar esa coyuntura, señalaba que "la persecución política obligaba a quienes se habían identificado con el gobierno depuesto en 1955 a una suerte de marginación tanto laboral como profesional" (PEÑA LILLO 2005, p. 63). Resaltaba que este había sido el caso de Hernández Arregui, a quien había alentado, junto con Jorge Abelardo Ramos (a quien luego nos referiremos), para que finalizara "lo que estimábamos un libro capital para el momento que vivía el país".

Estos factores incidieron en la virulencia de su ataque hacia la intelectualidad liberal triunfante en su ensayo Imperialismo y cultura. Recordemos que esta obra fue pergeñada luego de su expulsión universitaria y publicada originalmente en 1957 por la editorial Amerindia. ${ }^{8}$ En ella, Hernández Arregui intentará realizar "una historia crítica de las ideas" que legitimaron el proceso constitutivo del imperialismo cultural del que participaban las elites intelectuales argentinas.

En la lectura marxista que realiza Hernández Arregui, la imbricación entre economía, política y cultura no era un fenómeno estrictamente local, sino que, por el contrario, reflejaba las consecuencias culturales de la expansión del capitalismo a escala planetaria. De allí su preocupación por revisar cómo esas relaciones se habían

La FORJA fue fundada en 1935 por un grupo de intelectuales radicales disidentes a la decisión de la UCR de abandonar la abstención electoral, considerada como el último bastión de resistencia para deslegitimar el régimen de Agustín P. Justo. Este movimiento intentó recuperar las ideas de Hipólito Yrigoyen y fue tributario de los principios de la Reforma Universitaria de 1918 y de las ideas de la Alianza Popular Revolucionaria Americana. Entre sus miembros se destacan Juan B. Fleitas, Manuel Ortiz Pereyra, Arturo Jauretche, Homero Manzi, Oscar y Guillermo Meana, Luis Dellepiane, Gabriel del Mazo, Atilio García Mellid, Jorge Del Río, Darío Alessandro (padre) y Raúl Scalabrini Ortiz.

${ }^{6}$ En 1955, el gobierno de facto del general Eugenio Aramburu difundió el decreto 3.855, que ordenaba la disolución del partido peronista, con el fin de lograr su desaparición del escenario político. En marzo de 1956, promulgó el decreto 4.161, que, vigente hasta 1964, penaba con la cárcel a quien tuviera en su poder fotos de Perón y Eva Perón, pronunciara sus nombres o entonara la marcha peronista.

7 Sobre el proceso de "desperonización" de las universidades argentinas, véase Neiburg (1998). Respecto al accionar de las "comisiones investigadoras" instruidas por el gobierno de facto, véase Ferreyra (2018).

${ }^{8}$ Ese mismo año y por esa misma editorial, Jorge Abelardo Ramos publicó su Revolución y contrarrevolución en la Argentina. 
plasmado en el ámbito de la literatura internacional desde el siglo XIX hasta la actualidad, revisando el desenvolvimiento del romanticismo, el realismo y el naturalismo mediante el examen de la obra de Rilke, Valéry, Koestler Malraux, Kafka, Faulkner y Sartre, entre otros. El análisis de estos autores funcionaba como vía de acceso para abordar la crisis de la cultura burguesa, la situación del artista en el capitalismo, sus "públicos" y los circuitos de difusión de sus libros. También para problematizar la situación de dependencia del artista en relación con el mercado. A su vez, esta evaluación era el punto de partida de su crítica a la intelectualidad local, en la cual Hernández Arregui resaltaba los dispositivos que actuaban en la dependencia cultural de los intelectuales. Implícitamente, podría inferirse que ese señalamiento, además, le permitía poner de manifiesto su conocimiento sobre literatura europea como estrategia de legitimación de su propia autoridad intelectual en un contexto donde esa prerrogativa estaba vedada, en buena medida, para los pensadores peronistas.

Fue justamente ese lugar de alocución el que intentó habilitar Hernández Arregui; inauguró una senda que posibilitó la expresión de los intelectuales peronistas no solo perseguidos por la dictadura, sino también denostados por los exponentes culturales consagrados de la época, como los que se nucleaban en torno a la revista Sur, dirigida por Victoria Ocampo. Asimismo, sentó las bases desde las cuales arremeter contra sus antagonistas intelectuales. Desde la óptica de Hernández Arregui, el desvelamiento de las pulsiones ideológicas que habían actuado $-\mathrm{y}$ actuaban- en el proceder de la intelectualidad local permitiría comprender las causas que habían intervenido en el ocaso de la experiencia peronista en el poder del Estado.

La razón capital que moldea su juicio se encuentra en su interpretación acerca de que "toda la historia nacional (...) es la lucha contra la burguesía porteña ligada a la clase de hacendados bonaerenses" (HERNÁNDEZ ARREGUI [1957] 2005, p. 12). Para este pensador peronista, la literatura funcionó "como personificación encubierta de un ciclo económico" latifundista. Con Imperialismo y cultura, Hernández Arregui propone una revisión de la literatura argentina en la que intenta rastrear su contenido ideológico como instrumento de dominación cultural de los terratenientes porteños sobre el resto del país. Buscaba, así, dilucidar los dispositivos por medio de los cuales había operado la dominación ideológica de Buenos Aires sobre el "interior". Desde la óptica de este ensayista, la relación entre cultura, poder económico y político es intrínseca al desarrollo de las relaciones capitalistas en el país y funcionaría como el tamiz a través del cual evaluaría el proceso de extranjerización del pensamiento argentino.

Desde su visión, la generación del 30 actuó como "instrumento del imperialismo que se valió de ella para reforzar la conciencia falsa de lo propio y desarmar las 
fuerzas espirituales defensivas que luchan por la liberación nacional en los países dependientes". Esta denuncia sobre aquellas actitudes y procederes intelectuales, interpretados como desviados en relación con los intereses autóctonos, fue también una manera de posicionarse frente a los saberes instituidos y a las figuras consagradas de la intelectualidad nacional para reinsertarse él mismo como autor de una nueva interpretación sobre el devenir histórico argentino que lo reposicionaría como escritor "verdaderamente nacional".

El rechazo a las expresiones de la cultura popular se manifestaba entonces en una "literatura que confiesa su disgusto con el país y su deslumbramiento por lo europeo", también en "un arte evasivo que no quiere enfrentar su propia realidad", que, finalmente, no es otro que "el arte de las clases altas aliadas al imperialismo" (HERNÁNDEZ ARREGUI [1957] 2005, p. 117). En su lectura marxista sobre el fenómeno, el "arte no es mero reflejo del acontecer social, sino que sus relaciones con el ciclo económico se vislumbran en el orden del 'espíritu'". Y, en la Argentina, "a partir de ese año [1930] creció nuestro sentimiento de inferioridad", incentivado, según Hernández Arregui, por los intelectuales liberales porteños que privilegiaban los modelos de pensamiento extranjeros en detrimento de las expresiones populares del interior. Justamente, la exaltación de lo extranjero sobre lo local, sellado con el pacto "Roca-Runciman", cristalizaba "el correlato del extranjerismo económico y cultural de la oligarquía usurpadora del poder". Desde su interpretación,

el latifundio estrecha y comprime a los intelectuales adscriptos a su poder a través de diarios y órganos de la cultura oficial. Esta inteligencia fue en el orden de la cultura la sucursal poética de la renta territorial. Y así se puso también ella a espaldas al país (HERNÁNDEZ ARREGUI [1957] 2005, p. 116).

Allí residían los antecedentes históricos que explicaban la falta de comprensión de la intelligentsia local sobre el fenómeno peronista como realización de la voluntad popular. El ascenso de los y las trabajadoras a la vida política nacional atemorizó también a la pequeña burguesía influida por los juicios perniciosos de los intelectuales extranjerizantes que habían sancionado negativamente la llegada del pueblo al poder.

De un modo similar, el autor planteaba que la izquierda argentina "europeizante" había sancionado negativamente la identificación del proletariado argentino con la causa de Perón, sin advertir que en ese fenómeno se expresaba la llegada del pueblo históricamente marginado- como rector de los destinos de la nación. La gesta peronista 
ponía en vigencia los anhelos y reivindicaciones de los migrantes internos, reservorio de lo nacional en el poder del Estado. Los juicios negativos que los referentes del Partido Socialista (PS) y Comunista (PC) realizaban sobre el movimiento proscripto no hacía más que confirmar su extrañeza sobre el peronismo como expresión del pensamiento nacional y representación de los sectores sociales históricamente oprimidos.

Con su interpretación del pasado argentino, Hernández Arregui intenta reafirmar su carácter de pensador peronista y marxista en oposición a los modelos intelectuales existentes en su época, tanto de la izquierda como de la elite liberal. Asimismo, procura que su narración sobre el pasado argentino se diferencie de la del revisionismo del Instituto de Investigaciones Históricas "Juan Manuel de Rosas". Si bien en su texto es posible establecer una analogía con la obra de los hermanos Irazusta, su intención será la de marcar una clara distancia en virtud de su interpretación sobre el rol del "Restaurador de las Leyes" en el devenir nacional. Para el autor de Imperialismo y cultura, Rosas fue un exponente más del unitarismo latifundista porteño, aunque le reconoce el mérito de haber impedido la disgregación de las Provincias Unidas del Río de la Plata. No obstante, no encuentra motivos para exaltar su figura como defensor de los intereses nacionales; más bien, en todo caso, como garante del desarrollo latifundista bonaerense a expensas del interior. A juicio de Hernández Arregui, fue justamente esa disparidad entre el interior y Buenos Aires la que comenzó a saldarse con la experiencia peronista, injustamente apreciada por liberales, nacionalistas aristocratizantes e izquierdistas.

Este ajuste de cuentas entre las interpretaciones de la historia y el movimiento proscripto fue también una manera de intervención intelectual que abrió umbrales para interpelar los discursos dominantes sobre el peronismo. Hernández Arregui auspició, entonces, un contexto para discutir en otros términos las relaciones entre política y cultura y sus consideraciones que fueron duramente repelidas tanto por críticos literarios liberales como por militantes comunistas. ${ }^{9}$

Esa coyuntura que, a juicio del polemista, se vislumbra como revolucionaria se encuentra en relación con la imposibilidad del frondizismo de cumplir con el programa "nacional y popular" con el que prometió suturar el legado peronista, pero, por sobre todo, con las desinteligencias de los referentes del PC y PS que formaron parte de la Junta Consultiva que cogobernó con los militares que consumaron la autoproclamada

${ }^{9}$ Véase, por ejemplo, la reseña realizada por F. J. Solero en Ficción, enero- febrero 1958, n.11; J. C. Portantiero, "Nacionalismo y ser nacional", Nueva Expresión, enero de 1958, n.1; J. Gelman y J. C. Portantiero "Sobre el terrorismo crítico", Cuadernos de Cultura, mayo de 1958, n. 35. 
"Revolución Libertadora".10 Según nuestro autor, el colaboracionismo de socialistas y comunistas con la dictadura difícilmente podía calificarse como una alternativa revolucionaria para la clase obrera argentina. Tampoco lo era la solución democrática burguesa del gobierno de Frondizi, lo cual se confirmaba con la política represiva con la que se castigaba a los trabajadores que se resistían a la privatización de los bienes públicos, como se puso de manifiesto con la toma del Frigorífico Lisandro de la Torre. Desde su perspectiva, la posterior puesta en vigencia del Plan de Conmoción Interna (CONINTES) terminaba por confirmar el carácter coercitivo de las políticas del gobierno de la Unión Cívica Radical Intransigente (UCRI). ${ }^{11}$

En ese clima político se fue forjando la escritura de un nuevo ensayo que selló esa particular lectura del fenómeno peronista. La formación de la conciencia nacional, publicada en 1960 por la editorial Hachea -gestionada por el propio Hernández Arregui- fue la obra que consolidó su interpretación sobre el pasado argentino. ${ }^{12}$ En su prólogo, el autor establecía que "el propósito de este trabajo es el de contribuir desde la izquierda nacional -en oposición a la izquierda sin raíces en el país- al esclarecimiento de la cuestión nacional". Es decir, enunciar para el peronismo un espacio de relevancia dentro de la tradición de las izquierdas locales, al mismo tiempo que develar el proceso formativo de la conciencia nacional a lo largo de su historia - Hegel mediante- para resaltar, además, el carácter extranjerizante y antinacional de las izquierdas tradicionales respecto al peronismo.

En la lectura que Hernández Arregui realiza en este trabajo, las masas argentinas serían las realizadoras del destino nacional, expresión de "la cultura autóctona" y sujetos de la historia en tanto representarían las "creaciones colectivas, nacidas del paisaje y de una asociación de símbolos históricos [que] condensan las características espirituales de la comunidad entera" (HERNÁNDEZ ARREGUI [1960] 1973, p. 48).

\footnotetext{
${ }^{10}$ Con "frondizismo" nos referimos al nombre que recibió la gestión de gobierno desplegada por Arturo Frondizi, quien presidió constitucionalmente el país entre 1958 y 1962.

${ }^{11}$ En noviembre de 1959, por medio de la aplicación del decreto-ley 9.080/58, se facultaba judicialmente al Poder Ejecutivo Nacional y se legalizaba la intervención de la Fuerzas Armadas en temas de competencia civil. La aplicación del Plan CONINTES puso en manos de las Fuerzas Armadas, principalmente del Ejército, el desarrollo de las acciones contra las protestas políticas y sociales que se dieron durante el período.

12 El nombre "Hachea" remite a las iniciales del autor. Por medio de este emprendimiento editorial, pudo dar continuidad a la publicación de sus ensayos ante la imposibilidad de conseguir editores para sus escritos. Financió la publicación de su libro recurriendo a la venta adelantada de ejemplares, una metodología que volvería a aplicar para costear la edición de su tercera obra publicada en 1963, ¿Qué es el ser nacional? Al respecto, véase Reportaje exclusivo a Hernández Arregui. Una revolución nacional que rompa con el colonialismo, Compañero, 27 de agosto de 1963, n. 12, p. 4.
} 
Para este pensador, la fractura de esa unidad histórica fue originada por el accionar de la oligarquía vernácula. La obtención de beneficios económicos con el liberalismo europeizante junto con la adopción de instituciones políticas que copiaban el modelo inglés y los estandartes culturales franceses como baluartes de la "alta cultura" cohesionaban un "deber ser" cultural instrumentado por la intelligentsia local que negaba la vigencia del legado hispánico en las tradiciones populares argentinas, postulando así un proyecto civilizatorio foráneo. Desde la perspectiva de Arregui, eso que la elite política cultural llamaba "progreso" no era otra cosa que una de las formas con las que aquella legitimaba la dominación "al servicio del latifundio, el antiprogreso", en tanto perpetuaba las formas de explotación y opresión de las clases "auténticamente" nacionales.

Para el autor de La formación de la conciencia nacional, quienes erosionaban ese estado de cosas eran las masas argentinas en sus luchas por la liberación, tanto las del presente como las del pasado, a pesar de que la historiografía liberal había omitido su presencia y la revisionista había rechazado ese umbral de igualación social que habían puesto en acto por medio del peronismo. Rescataba Arregui las iniciativas de los intelectuales vinculados a la FORJA en el proceso evolutivo de la formación de la conciencia nacional, en tanto habían colaborado para desentrañar las claves de la sumisión argentina al imperialismo británico. El autor se refería particularmente a los aportes de Raúl Scalabrini Ortiz, a quien dedicaba su nuevo libro. Asimismo, subrayaba que esa corriente política e intelectual había funcionado como una especie de "puente histórico" entre la experiencia popular yrigoyenista y la peronista, creando un "eslabón de la cadena que explica desde 1916 en adelante, el paulatino ascenso de las masas nacionales a la vida plenamente histórica de la Argentina".

Esa vitalidad plenamente histórica hace alusión al protagonismo político que en ambas experiencias tuvieron los sectores populares. No obstante, para Hernández Arregui, el déficit de los forjistas había residido en no comprender la complejidad del movimiento obrero argentino. Una cuestión que sí habría sido entendida por Perón y que resultó nodal para la revolución popular democrática burguesa que se inició el 17 de octubre de 1945. Ese 17 de octubre no hacía más que confirmar que el peronismo era la verdadera izquierda nacional en le medida en que encarnaría la presencia de las masas como actoras de su historia. A su juicio, la formación de la conciencia nacional también resultaba de la experiencia que durante el primer peronismo las clases populares y auténticamente nacionales habían realizado sobre las condiciones de sujeción y de explotación a las cuales estuvieron históricamente sometidas. En ese saberse sometidos, pero también potencialmente actores de su propia liberación y de su propia historia, los 
trabajadores peronistas habrían encontrado la fuerza para impulsar las luchas para el ejercicio del poder y lograr la unidad nacional en detrimento de las potestades que se arrogaban las fuerzas extranjerizantes que las constreñían.

\section{La izquierda nacional y las disputas por el sentido político de la historia}

Resulta relevante detenerse en algunos de los debates que la publicación de La formación de la conciencia nacional concitó en el ámbito de las izquierdas locales. En ese sentido, la atención de disidentes frondizistas y referentes de las izquierdas a esta obra puede examinarse a partir de un conjunto de reseñas publicadas en el semanario El Popular. ${ }^{13}$ Allí, Carlos Strasser situaba la ensayística de Hernández Arregui en la cosmogonía de la izquierda nacional emergente, junto con Rodolfo Puiggrós, Ismael Viñas, John William Cooke y Jorge Abelardo Ramos. ${ }^{14}$ Para Strasser, estos intelectuales, "desde ángulos no del todo coincidentes, enfocan la realidad argentina con un criterio marxista apreciablemente distinto al tradicional criterio marxista proclamado por los partidos Socialista y Comunista". En esa órbita ubicaba el reciente ensayo histórico del pensador peronista, señalando que, si bien su lectura "ayuda buenamente a entender el país," el mayor déficit de su reflexión residía en que no abordaba adecuadamente "la cuestión nacional y el marxismo, uno de los temas decisivos para poder fundar esta nueva posición de izquierda" a la que el libro intentaba contribuir. Asimismo, señalaba que eran discutibles las tesis elaboradas por el filósofo acerca de la cultura nacional, el papel del ejército en la lucha por la liberación y el bonapartismo peronista. ${ }^{15}$

semanario El Popular se inició como una publicación de oposición a Frondizi, aunque varios de sus artífices habían participado de su gobierno. Durante sus 13 entregas intentó reflejar los debates políticos de la época en relación con las promesas truncas del desarrollismo, la vigencia del peronismo en los sectores populares y la crisis de las izquierdas locales, que se evidenciaba en el surgimiento de una ensayística crítica a las posiciones tradicionales de los partidos socialistas y comunistas. Entre sus colaboradores más destacados se encuentran Arturo Jauretche, José Nun, Ismael Viñas, Rodolfo Ortega Peña, John William Cooke y Alicia Eguren.

${ }^{4}$ STRASSER, Carlos. Acerca de una Izquierda Nacional. El Popular, 14 de septiembre de 1960, n. 1, p. 10. Strasser comenzó su militancia política como dirigente estudiantil en el Movimiento Universitario Reformista. En 1959, organizó un ciclo de discusiones sobre "Las izquierdas en el proceso argentino", en el que participaron Silvio Fondizi, Rodolfo Ghioldi, Alexis Latendorf, Nahuel Moreno, Rodolfo Puiggrós, Librorio Justo, Jorge A. Ramos, Esteban Rey e Ismael Viñas. Más tarde, las discusiones fueron editadas en un libro bajo el mismo título del ciclo. Una de las preguntas a las que los expositores debieron responder refería a si era posible concebir el peronismo como la "verdadera" izquierda nacional.

${ }^{15}$ Cabe aclarar que la noción de bonapartismo no fue utilizada por Hernández Arregui para caracterizar el gobierno de Perón, sino que, por el contrario, es próxima a la interpretación realizada por Jorge Abelardo Ramos (1959) en Revolución y contrarrevolución en la Argentina, lo cual nos habla sobre las adscripciones políticas del reseñista antes que de los entendimientos del filósofo peronista. 
De hecho, en un reportaje a Ramos publicado números más tarde en la misma revista, al comentar las contribuciones del nuevo libro de Hernández Arregui, si bien declaraba que celebraba la iniciativa reflexiva del "único intelectual marxista con el que cuenta el movimiento nacional", finalizaba afirmando que los juicios del autor de La formación... reflejaban su posición como "culminación del forjismo pequeño burgués en la nueva época" antes que un análisis histórico señero del materialismo histórico. ${ }^{16}$

La respuesta de Hernández Arregui se dirige no solo a corregir la ubicación política que le endilga Ramos, sino que, por sobre todo, a esclarecer el significado que la noción de izquierda nacional condensaba para él y, de esa forma, evitar el usufructo que realizaban intelectuales que, desesperanzados por la traición de Frondizi como era el caso de Ismael Viñas- o por la soledad de sus apuestas políticas como las de Ramos-, apelaban a dicha noción para inscribir sus textos y sus entendimientos sobre el proceso argentino. ${ }^{17}$ Para el autor de La formación..., el término "izquierda nacional" expresaba "la comprensión histórica del contenido nacional, antimperialista y revolucionario del peronismo como movimiento de masas". Acto seguido, arremetía contra la evaluación que Ramos había emitido sobre su nuevo libro. El punto de anclaje de la crítica de Hernández Arregui radicaba en que el autor de Revolución y contrarrevolución....

piensa que hay que superar a Perón mediante un partido socialista nacional. Y yo sostengo que si Perón no estuviese a la altura de la revolución nacional y de sus objetivos posibles, las masas lo hubiesen abandonado. Esta posición del proletariado argentino no aclara, en otro orden, algo que a Ramos le resulta un tanto inexplicable. Mi condición de peronista y marxista. Soy peronista porque soy marxista. Es decir, por adecuación objetiva de mi pensamiento al grado de desarrollo de la conciencia política del proletariado nacional, cuyo símbolo es Perón. Perón es el eje de cohesión nacional de las masas. El único que no ha quebrado el imperialismo (HERNÁNDEZ ARREGUI 1960, p.10).

Desde su perspectiva, resultaba capital considerar a Perón y a su movimiento como eje y vector del socialismo en el país, una cuestión que su antiguo editor y compañero

16 VALENZUELA, Carlos. Con Abelardo Ramos. Un reportaje de Carlos Valenzuela. El Popular, 3 de noviembre de 1960, n. 8, p. 2.

Esta inferencia resulta de la atención que mereció en los ámbitos intelectuales progresistas el libro de Ismael Viñas (1960) Orden y Progreso. La era del frondizismo, publicado casi en simultáneo al de Hernández Arregui, y que, en espacios políticos e intelectuales como los de la revista El popular, era inscripto dentro de la órbita de la izquierda nacional. Al respecto, véase STRASSER, Carlos. Otra vez sobre una izquierda nacional, El Popular, 21 de septiembre de 1960, n. 2, p. 5. 
de ruta se negaba a reconocer y que, unos años más tarde, terminaría por desencadenar un quiebre de relaciones cuando aquel impulsase la formación del Partido Socialista de la Izquierda Nacional (PSIN).

Por otro lado, puede apreciarse en las intervenciones de Hernández Arregui la intención de dotar de inteligibilidad la comunión entre marxismo y peronismo. La difusión de sus posiciones por medio de sus libros y de los ámbitos de debate que habilitaba la prensa crítica de la época abría un espacio para hacer pública una nueva síntesis interpretativa para concebir la trascendencia de la causa peronista en cualquier proyecto político transformador imaginable. Esta directriz se afirmaba en la revisión histórica que el ensayista realizaba al aunar el conocimiento de las masas oprimidas en las luchas pretéritas por su liberación con su adherencia al partido proscripto, lo cual se manifestaba como expresión de la conciencia verdaderamente nacional que los intelectuales del establishment, de la izquierda abstracta-extranjerizante y del revisionismo aristocratizaste, se negaban a considerar.

Puede considerarse que, con la búsqueda de consolidación de su empresa historiográfica, Hernández Arregui intentó consolidarse en tres niveles. Con su primer libro, procuró rehabilitar sus credenciales de autoridad, vulneradas por la intelectualidad liberal que celebraba el advenimiento de la "Revolución Libertadora" y el desplazamiento de los referentes culturales y académicos que habían ejercido cargos durante el primer peronismo. ${ }^{18}$ Asimismo, el "desvelamiento" de las condiciones históricas de reproducción de las elites culturales dependientes del latifundismo oligarca atado al imperialismo capitalista, como su denuncia a las izquierdas extranjerizantes impedidas de comprender el fenómeno peronista debido a sus modelos de pensamiento foráneos, constituyó una estrategia para minar la autoridad intelectual de sus oponentes para comprender la historia y la cultura argentina. Si bien el revisionismo de los años 1930 había contribuido a la construcción de una "contrahistoria" liberal, sus posiciones aristocratizantes, junto con el temor a la democracia de masas, reducían su capacidad de análisis para interpretar positivamente el advenimiento de las masas en el destino político de la nación.

Un segundo nivel de consolidación político-intelectual se advierte en las discusiones que mantiene con referentes de las izquierdas, disidentes de las líneas oficiales del PC y del PS y que, como Ramos, proponen líneas interpretativas alternativas para explicar el fenómeno peronista. La disputa con el autor de Revolución y contrarrevolución... sobre el alcance del término "izquierda nacional" puede resultar representativa de esta

${ }^{8}$ Sobre el proceso de "desperonización" universitaria, véase Neiburg (1998, p. 196-204). 
cuestión. Para Hernández Arregui, esa noción refería, antes que a la conformación de un partido político - como el que Ramos impulsó en 1962-, a una corriente ideológica que contribuyera "al esclarecimiento de la cuestión nacional a partir de la propia realidad y no de realidades foráneas". ${ }^{19}$ Esto implicaba la comprensión del contenido revolucionario del peronismo como encarnación popular de la realización política de la nación. De allí que considerara que "el caso de Fidel Castro en Cuba refleja esta etapa histórica más avanzada de la lucha de América Latina y del mundo colonial en crisis y de la cual Perón es un antecedente necesario". ${ }^{20}$

Esa cuestión, desde la perspectiva del autor de Imperialismo y cultura, era cada vez más evidente entre las nuevas generaciones intelectuales que se acercaban al peronismo, lo cual confirmaba la paulatina "nacionalización de las izquierdas". Un índice de esa cuestión se observa en el análisis crítico que realiza Rodolfo Ortega Peña sobre la trayectoria intelectual de Lugones publicado en la revista El Popular. Este abogado, antiguo militante de la juventud comunista, elegía interpretar la obra política y literaria del "Poeta nacional" sirviéndose de las claves de lectura contenidas en la ensayística de Hernández Arregui. Consideraba que la existencia misma del autor de Romances del Río Seco representaba "un momento esencial en el proceso de formación de nuestra conciencia nacional," dado que su historia de vida podía leerse como caso testigo "de las dos negaciones, la de la izquierda abstracta y la de la oligarquía", que caracterizaban el accionar de los intelectuales argentinos. ${ }^{21}$

Por otro lado, y en estrecha vinculación con los dos niveles anteriores, se advierte un tercer nivel de intervención política e intelectual de Hernández Arregui hacia el interior del peronismo. Si a principios de 1960 se afirmaba en la órbita de lo privado por medio de su relación epistolar con John William Cooke, ${ }^{22}$

\footnotetext{
9 A mediados de 1962, Ramos impulsa la fundación del Partido Socialista de la Izquierda Nacional (PSIN), que, si bien, tal como menciona Ribadero, aunó en su seno a "jóvenes de clase media ilustrada, inmersos en una búsqueda por canalizar y conjugar un tipo de intervención tanto política como intelectual (241)", como Ernesto Laclau, Adriana Puiggrós y Félix Schuster, entre otros, también generó rispideces y rupturas con antiguos compañeros de ruta que rechazaron la iniciativa del autor de Revolución y contrarrevolución... de organizar un espacio político de izquierda por fuera del peronismo. Tal fue el caso de Hernández Arregui, para quien la iniciativa de Ramos no solo era errada porque se impulsaba en un contexto en el que se estaba produciendo un "giro a la izquierda" en el peronismo, sino que también dividía voluntades en torno a una u otra opción política (PIÑEIRO IÑIGUEZ 2007, p. 64).

20 HERNÁNDEZ ARREGUI. Sobre la revolución cubana. Política (segunda época), febrero de 1961, año I, n. 2.

${ }^{21}$ ORTEGA PEÑA, Rodolfo. Lugones. Escritor en un país colonial. El Popular, 3 de noviembre de 1960, n. 8 , p. 5.

2 COOKE, J. W.; HERNÁNDEZ ARREGUI, J.J. Correspondencia (1960-1964). Fondo John William CookeAlicia Eguren, Biblioteca Nacional Argentina, caja 6, carpeta 3.
} 
se expande hacia lo público mediante la difusión de sus libros en semanarios destinados a la militancia peronista como Compañero. ${ }^{23}$

Estas intervenciones se dan en un contexto en el que se está produciendo, para algunos observadores de la época, un "giro a la izquierda" en el interior del movimiento proscripto (PRADO ACOSTA 2013, p. 64-65; PIÑEIRO IÑIGUEZ 2007, p. 64). Los signos de este corrimiento se vinculaban con la relevancia política que adquirían ciertos liderazgos sindicales, tal como se expresó en la candidatura a gobernador de la provincia de Buenos Aires del dirigente textil Andrés Framini en las elecciones que se desarrollaron en marzo de 1962, en las cuales, por primera vez luego del golpe de Estado de 1955, se habilitó la participación del peronismo en los comicios. ${ }^{24}$ Sin embrago, al conocerse los resultados favorables para este último, las Fuerzas Armadas intervinieron el Ejecutivo nacional para invalidar los comicios y forzar la renuncia del presidente Frondizi. Estos factores, junto con el recrudecimiento de la represión estatal a militantes peronistas, incidieron en la configuración de discursos y prácticas contestatarias en el interior del movimiento, tal como puede apreciarse en el programa obrero de Huerta Grande (1962) y en las páginas del semanario Compañero. ${ }^{25}$

En dicha revista, Hernández Arregui publicita su nuevo libro, publicado en 1963, ¿Qué es el ser nacional? La noticia de la aparición de esta nueva obra es ilustrada con la reproducción de una carta de felicitación que su "maestro", Rodolfo Mondolfo, le hace llegar para congraciarse por la aparición de su nuevo ensayo a pesar de no compartir por completo sus conclusiones. ${ }^{26}$ El reportaje en cuestión no gira en torno a los contenidos del nuevo ensayo, sino en aclarar cuáles son las credenciales políticas de su autor para afirmar su condición como pensador peronista. En ese sentido, Hernández Arregui se esfuerza por desmentir a los "difamadores" que, como Rogelio Frigerio, intentaban emparentarlo con el "nacionalismo" de derecha cercano a Marcelo Sánchez Sorondo. Por otro lado, planteaba que ciertos nucleamientos identificados equivocadamente con la "izquierda nacional" se habían aferrado a esos argumentos para incriminarlo de colaboracionista con el catolicismo de derecha. De allí que haya intentado desactivar

Este semanario, dirigido por Mario Valotta, contó con 79 números, publicados entre el 7 de junio de 1963 y la $1^{\text {a }}$ quincena de abril de 1965.

${ }^{24}$ Sobre el crecimiento político de los liderazgos sindicales en el contexto de las elecciones de 1962, véase Smulovitz (1988).

${ }^{25}$ Hemos analizado esta última cuestión en Caruso (2019b).

${ }^{6}$ Reportaje exclusivo a Hernández Arregui. Una revolución nacional que rompa con el colonialismo. Compañero, 27 de agosto de 1963, n. 12, p. 4. Para Hernández Arregui, Mondolfo era el "único europeo que ha contribuido al desarrollo de los estudios filosóficos en la Argentina". 
los prejuicios vertidos por sus oponentes políticos e insistido en presentarse como un "hombre de Ideas" del movimiento proscripto. Se reconoce a sí mismo como un "peronista de la izquierda nacional" y explicita su intención "de contribuir, en el plano exclusivamente ideológico a la creación de una tendencia de 'izquierda nacional' peronista".

Desde la perspectiva de Hernández Arregui, este entendimiento no devenía de un conocimiento abstracto, sino del devenir histórico de los sectores populares a través del peronismo. De allí que planteara que "las masas peronistas, en tanto clase obrera, están en la izquierda. $Y$ son nacionales. $Y$ de la 'izquierda nacional', surgida después de la caída de Perón". Más aún, entendía que la presencia del peronismo y la labor teórica de la "izquierda nacional", es decir, la influencia de su propia obra, junto con la adherencia de las y los trabajadores argentinos al peronismo habían sido los factores decisivos que habían incidido en la nacionalización de vastos sectores populares de izquierda que, hasta hacía poco tiempo, daban la espalda a la cuestión nacional. Por ello, se esforzaba en aclarar que

La "izquierda nacional" peronista aspira a contribuir a esa renovación, dentro de las características del movimiento nacional de masas que la engloba y determina. Esta es la tarea que me propuse al crear el término "izquierda nacional", al servicio ideológico de las masas nativas y latinoamericanas para reflejar y enriquecer la lucha anticolonialista en la Argentina y en la América Latina (HERNÁNDEZ ARREGUI).

Esta declaración resulta ilustrativa de varias de las cuestiones que subyacen en la narrativa de la historia delineada por Hernández Arregui. Por un lado, reconocer el peronismo como el fenómeno nacional por medio del cual la historicidad de las "masas" populares se reinsertaba en el devenir de la construcción nacional no como un apéndice de determinados liderazgos, sino como la carnadura de la nación. Por ello el peronismo, en su propio desenvolvimiento histórico, era la "verdadera" izquierda nacional, la cual se afirmaba en la adhesión popular al movimiento proscripto. Por otro lado, confirmar que, desde su salida del poder del Estado, en el seno del peronismo había emergido la izquierda nacional, otorgándole un carácter intrínseco que le era negado por polemistas como Ramos y los sectores considerados de "derecha" o burocratizados del movimiento. ${ }^{27}$ Desde la perspectiva de Hernández Arregui, su reflexión sobre el acontecer histórico nacional posibilitaba advertir la radicalidad del peronismo y el

Sobre esta última cuestión, puede consultarse Besoky (2016). 
surgimiento de la verdadera izquierda nacional, no situada en abstracciones foráneas, sino en la materialidad de su realización histórica.

Según su autor, con ¿Qué es el ser nacional? intentaba contribuir al proceso de "nacionalización de las izquierdas", el cual se completaría en función del compromiso que los intelectuales asumieran con los problemas de su tiempo. Esto implicaba reconocer en los obreros peronistas el único sector "consecuentemente nacional" y, por ello, el núcleo articulador de la emancipación latinoamericana iniciada en el pasado por San Martín, Bolívar y Ugarte. El accionar de los trabajadores ponía de manifiesto la centralidad de los sectores populares en la transformación de la historia nacional.

Por otro lado, recordaba que la Revolución de Mayo se había producido por la crisis del sistema virreinal antes que por la acción deliberada de las masas. A partir de entonces, la separación de España había sido usufructuada por las minorías urbanas que imponían sus intereses particulares en detrimento de los colectivos. Las elites nativas habían irrumpido sobre las prerrogativas políticas y económicas de los pueblos del interior en virtud de su incorporación al mercado internacional. La derrota del interior frente a Buenos Aires se advertía transitoria, pues la pregnancia de lo "auténticamente" nacional pervivía en sus tradiciones y en la lucha que durante su devenir histórico las masas habían emprendido contra la opresión política y la explotación económica orquestada desde Buenos Aires. Asimismo, su vitalidad se ponía de manifiesto en la vigencia de la causa peronista y, a escala continental, en la égida cubana, que alumbraba un camino de emancipación para los pueblos latinoamericanos.

Hernández Arregui concibió la historia de las ideas como la consumación del autoconocimiento de la sociedad. En esta concepción subyace el gesto hegeliano en el que "la reflexión histórica de una época le permite avanzar más allá de sí misma" (ACHA 2009, p. 318). Y fue en función de ese entendimiento que introdujo el ejercicio histórico de la praxis historiográfica para la izquierda peronista. Al reconocerse como actualidad del pasado nacional y continuidad socialmente superadora del pensamiento antinacional, el peronismo obtendría la claridad teórica para abocarse al combate por el lugar que la historia le tendría reservado. La "madurez ideológica" a la que Hernández Arregui busca contribuir habilitaría una "unidad superior del espíritu" articulada y unificada en la historia de la nación. Esa autoconciencia procrearía una nueva figura histórica para el peronismo.

Para las siguientes generaciones de intelectuales de peronistas, la obra de Hernández Arregui inauguró "una manera inédita de 'leer' nuestro pasado cultural, más integradora y comprensiva que cualquier otra previa o coetánea". Asimismo, reconocían 
"su inestimable aporte a la nacionalización mental de las capas medias intelectuales y a la clarificación ideológica de la clase trabajadora sobre la base de las grandes banderas del justicialismo" (ROMANO 1974, p. 25-28).

\section{Conclusiones}

Al comienzo de esta indagación señalamos la pertinencia de considerar las claves conceptuales brindadas por Pocock para apreciar que, en cierto sentido, toda historiografía es un fenómeno político en sí mismo. Siguiendo esta propuesta teórica, puede interpretarse que, en ciertas circunstancias, la emergencia de nuevas historiografías puede estar asociada a demandas políticas y sociales de otorgarle inteligibilidad a determinados actores, eventos y fenómenos no inscriptos en las narrativas históricas vigentes. De allí que la competencia de relatos sobre el pasado condense un conjunto de disputas sobre el sentido de la historia como una manera de dirimir las disputas políticas que se despliegan en el presente.

Entendemos que un abordaje de esta índole permitió apreciar con mayor precisión las características de la empresa historiográfica emprendida por Hernández Arregui en los albores de la proscripción al peronismo.

Unas de las marcas de autor de esta ensayística histórica fue el permanente cuestionamiento de las posiciones ideológicas de sus contrincantes para comprender el pasado nacional y su actualidad por medio del peronismo. Estos cuestionamientos pueden ser considerados como una modalidad de intervención que, implícitamente, le permitió validar su propia autoridad como intelectual peronista en un momento en el que sus credenciales como tal habían sido impugnadas por el hostigamiento institucional de los funcionarios de la "Revolución Libertadora" y los referentes culturales del establishment.

Asimismo, Hernández Arregui habilitó un contextoque permitió otorgarle inteligibilidad a su manera de entender el peronismo: "Soy peronista porque soy marxista", decía a principios de la década de 1960 y, en ese decir, inauguró una formulación que creció en visibilidad y contundencia en el transcurso de los 18 años en los que el peronismo estuvo proscripto.

El autor de Imperialismo y cultura encontró una manera de fundamentar los motivos por los cuales la elite argentina se negaba a comprender el fenómeno peronista como una fuerza política "verdaderamente" nacional. Esa veracidad de lo nacional que se 
realizaba en el peronismo se ponía de manifiesto en las masas obreras del interior que se identificaban con el gobierno depuesto. En ellas residía el "verdadero" sentido de lo nacional, que las interpretaciones de los intelectuales liberales y de las izquierdas tradicionales obturaban, exponentes como eran de un pensamiento extranjerizante que impedía la realización de la conciencia nacional.

Esa renarración de la historia implicaba, a su vez, una reinterpretación de las matrices culturales sobre las que se habían erigido los relatos instituidos para la comprensión del pasado argentino, en un contexto donde esos estaban en crisis en función de su imposibilidad de otorgarle inteligibilidad a la persistencia del peronismo como fenómeno político.

En ese sentido, la empresa historiográfica de Hernández Arregui fue efectiva al brindar una lectura del pasado nacional que resituaba el movimiento proscripto en el proceso formativo de la nación argentina como expresión política de las gestas populares. La difusión de estas premisas a lo largo de la década de 1960 se observó en las colaboraciones realizadas en distintas revistas políticas de la época y en las polémicas que el autor entabló con distintos referentes intelectuales del progresismo local.

Creó, junto a otros actores, un espacio para la realización intelectual por medio de una relectura que conectaba las luchas populares del pasado con la actualidad del peronismo en un contexto en el que éste era percibido como la única fuerza política con capacidad de suturar la crisis de legitimidad que atravesaba el país. En definitiva, la demanda de nuevas interpretaciones de la historia encontró en la obra de Hernández Arregui un vínculo pretérito con las gestas del presente que contribuyó a delinear los marcos simbólicos de la izquierda peronista como cultura política.

\section{REFERENCIAS}

$\mathrm{ACHA}$, Omar. Historia crítica de la historiografía argentina. Las izquierdas en el siglo XX. Buenos Aires: Prometeo, 2009.

ALTAMIRANO, Carlos. Peronismo y cultura de izquierda. Buenos Aires: Temas Grupo Editorial, 2001. 
BESOKY, Juan Luis. La derecha peronista: Prácticas políticas y representaciones (1943-1976). 2016. Tesis (doctorado en Historia). Facultad de Humanidades y Ciencias de la Educación, Universidad Nacional de La Plata, La Plata, 2016.

CARUSO, Valeria. Derivas de la izquierda peronista a través de las lecturas de 18 de marzo y Compañero. Avances del Cesor, Rosario, v. 16, n. 21, p. 41-61, 2019b.

CARUSO, Valeria. Izquierda peronista como cultura política (1955-1973). Archivos, Buenos Aires, v. 8, n. 15, p. 77-98, 2019a.

COOKE, John William; HERNÁNDEZ ARREGUI, Juan José. Correspondencia (1960-1964). Fondo John William Cooke- Alicia Eguren, Biblioteca Nacional Argentina, caja 6, carpeta 3.

DEVOTO, Fernando. Reflexiones en torno de la izquierda nacional y la historiografía. In: DEVOTO, Fernando; PAGANO, Nora (comp.). La historiografía académica y la historiografía militante en Argentina y Uruguay. Buenos Aires: Biblos, 2004.

FERREYRA, Silvana. El peronismo denunciado. Antiperonismo, corrupción y comisiones investigadoras durante el golpe de 1955. Buenos Aires: Eudem-GEU, 2018.

GALASSO, Norberto. J. J. Hernández Arregui. Del peronismo al Socialismo. Buenos Aires: Colihue, 2012.

GELMAN, Juan; PORTANTIERO, Juan Carlos. Sobre el terrorismo crítico. Cuadernos de Cultura, Buenos Aires, n. 35, mayo 1958.

GOEBEL, Michael. "Redes e instituciones del revisionismo histórico argentino, 19551973". In: X Jornadas Interescuelas. Departamentos de Historia, Escuela de Historia de la Facultad de Humanidades y Artes, Universidad Nacional del Rosario. Rosario, 2003.

GOEBEL, Michael. La Argentina partida: Nacionalismos y políticas de la historia. Buenos Aires: Prometeo Libros, 2013.

HALPERÍN DONGHI, Tulio. El revisionismo histórico argentino como visión decadentista de la historia nacional. Ensayos de historiografía. Buenos Aires: El cielo por asalto, 1996.

HERNÁNDEZ ARREGUI, Juan José. ¿Qué es el ser nacional? Buenos Aires: Hachea, 1963. 
HERNÁNDEZ ARREGUI, Juan José. Doble enfoque sobre la izquierda nacional. El popular, Buenos Aires, n. 10, p. 10, 17 nov. 1960.

HERNÁNDEZ ARREGUI, Juan José. Imperialismo y cultura. Buenos Aires: Ediciones Continente, [1957] 2005.

HERNÁNDEZ ARREGUI, Juan José. La formación de la conciencia nacional 19301960. Buenos Aires: Plus Ultra, [1960] 1973.

NEIBURG, Federico. Los intelectuales y la invención del peronismo. Buenos Aires: Alianza, 1998.

ORTEGA PEÑA, Rodolfo. Lugones. Escritor en un país colonial. El Popular, Buenos Aires, n. 8, p. 5, 3 nov. 1960.

PEÑA LILLO, Arturo. Memoria de papel. Los hombres y las ideas de una época. Buenos Aires: Ediciones Continente, 2005.

PIÑEIRO IÑIGUEZ, Carlos. Hernández Arregui, intelectual peronista. Buenos Aires: Siglo XXI, 2007.

POCOCK, John G. A. Pensamiento político e historia. Ensayos sobre teoría y método. Madrid: Akal, 2011.

PORTANTIERO, Juan Carlos. Nacionalismo y ser nacional. Nueva Expresión, Buenos Aires, n.1, enero 1958.

PRADO ACOSTA, Laura. Sobre lo 'viejo' y lo 'nuevo': el Partido Comunista argentino y su conflicto con la Nueva Izquierda en los años sesenta. A Contracorriente. Una revista de historia social y literatura de América Latina, North Carolina, v. 11, n.1, p. 63-85, 2013.

RAMOS, Jorge Abelardo. Revolución y contrarrevolución en la Argentina. Buenos Aires: Amerindia, 1959.

Reportaje exclusivo a Hernández Arregui. Una revolución nacional que rompa con el colonialismo, Compañero, Buenos Aires, n. 12, p. 4, 27 agosto 1963. 
RIBADERO, Martín. Tiempo de profetas. Ideas, debates y labor cultural de la izquierda nacional de Jorge Abelardo Ramos (1945-1962). Buenos Aires: Universidad Nacional de Quilmes, 2017.

ROMANO, Eduardo. Hernández Arregui: un pensador nacional. Crisis, Buenos Aires, n. 19, p. 25-28, 1974.

SIRINELLI, Jean-François. Las elites culturales. In: RIOUX, Jean-Pierre; SIRINELLI, Jean-François, Para una historia cultural. México: Taurus, 1999.

SKINNER, Quentin. Significado y comprensión en la historia de las ideas. Prismas: revista de historia intelectual, Buenos Aires, n. 4. p. 149-194, 2000.

SMULOVITZ, Catalina. Crónica de un final anunciado: las elecciones de marzo de 1962. Desarrollo Económico, Buenos Aires, v. 28, n. 109, p. 105-119, 1988.

SOLERO, Francisco Jorge. Ficción, Buenos Aires, n.11, p. 173-182, enero-feb. 1958.

STORTINI, Julio. Polémicas y crisis en el revisionismo argentino: el caso del Instituto de Investigaciones Históricas Juan Manuel de Rosas (1955-1971). In: DEVOTO, Fernando; PAGANO, Nora (comp.). La historiografía académica y la historiografía militante en Argentina y Uruguay. Buenos Aires: Biblos, 2004.

STRASSER, Carlos. Acerca de una Izquierda Nacional. El Popular, Buenos Aires, n. 1, p. 10, 14 sept. 1960.

STRASSER, Carlos. Las izquierdas en el proceso político argentino. Buenos Aires: Editorial Palestra, 1959.

STRASSER, Carlos. Otra vez sobre una izquierda nacional. El Popular,Buenos Aires, n. 2, p. 5, 21 sept. 1960.

VALENZUELA, Carlos. Con Abelardo Ramos. Un reportaje de Carlos Valenzuela. El Popular; Buenos Aires, n. 8, p. 2, 3 nov. 1960.

VIÑAS, Ismael. Orden y Progreso. La era del Frondizismo. Buenos Aires: Editorial Palestra, 1960. 


\section{INFORMACIÓN ADICIONAL}

\section{BIOGRAFÍA ACADÉMICA}

Valeria A. Caruso es Doctora en Historia por la Facultad de Filosofía y Letras de la Universidad de Buenos Aires (FFyL-UBA). Se desempeña como docente de la carrera de Historia en esa casa de estudios. Desarrolla tareas de investigación como becaria posdoctoral del Consejo Nacional de Investigaciones Científicas y Técnicas, y del Instituto de Investigaciones de Estudios de Genero de la Facultad de Filosofía y Letras de la Universidad De Buenos Aires (CONICET/IIEGE). Se especializa en historia intelectual argentina durante el periodo de la proscripción al peronismo.

\section{DIRECCIOON PARA CORRESPONDENCIA}

Puan $4804^{\circ}$ piso, CABA, Bs. As., 1406, Argentina.

\section{FINANCIACIÓN}

Consejo Nacional de Investigaciones Científicas y Técnicas.

\section{CONFLICTO DE INTERESES}

Sin conflicto de interés declarado.

\section{APROBACIÓN DEL COMITÉ DE ÉTICA}

No se aplica.

\section{MÉTODO DE EVALUACIÓN}

Sistema doble ciego de revisión por pares.

\section{EDITOR RESPONSABLE}

Omar Acha - Editor Executivo

\section{DERECHOS DE AUTOR}

Copyright (c) 2020 História da Historiografia: International Journal of Theory and History of Historiography. 


\section{LICENCIA}

Este es un artículo distribuido en acceso abierto bajo los términos de la Licencia Creative Commons Atribución-NoComercial-SinDerivadas 4.0 Internacional.

HISTORIA DE REVISIÓN POR PARES

Recibido el: 5 de octubre de 2020.

Cambiado en: 16 de diciembre de 2020.

Aceptado el: 17 de diciembre de 2020. 